\title{
Molecular genetics, diagnosis and management of clear cell sarcoma of hand
}

\author{
Dr.N.Mariappan ${ }^{1}$, Dr.Shashikala. $V^{2}$ \\ ${ }^{I}$ Associate Professor of Plastic Surgery, \\ ${ }^{2}$ Assistant Professor of Pathology (Vydehi Institute of Medical Sciences and Research Centre, Bengaluru, India)
}

\begin{abstract}
:
Synonyms: Clear cell sarcoma of soft tissue, Clear cell sarcoma of the tendons and aponeuroses, malignant melanoma of the soft parts.

Background: Rodriguez-Martin, Ortiz-Cruz, Del Rio, Vivanco, \& Lopaz-Amor in 2011 stated "Clear cell sarcoma is a high-grade soft tissue sarcoma seen in adolescents and young adults, with melanosytic differentiation typically involving tendons and aponeuroses". Clear cell sarcoma of soft tissue (CCSST) was originally described by Dr. Franz M. Enzinger in 1965 as a distinct entity of tumors arising from tendons and aponeuroses in young adults. Clear cell sarcoma (CCS) of soft tissue is a rare sarcoma with morphologic similarities to malignant melanoma. They are characterized by a distinct genetic background including a chromosomal translocation $t(12 ; 22)(q 13 ; q 12)$, or a resultant EWSR1-ATF1 fusion gene. The lower limbs are involved more commonly. Clear cell sarcoma has been reported in other tissues such as bone, colon and gastrointestinal tract. The clear cell sarcoma that occurs in relation to the gastrointestinal tract has a variant fusion gene EWSRI-CREBI and they are re-designated as gastrointestinal neuroectodermal tumor (GNET). Material and method: A 21 years old female with a chronic recurrent swelling of the left mid finger was diagnosed as epithelioid sarcoma on histopathological examination. Immunohistochemistry was done with basic tumor markers panel and a diagnosis of clear cell sarcoma was confirmed.
\end{abstract}

Result: Immunohistochemistry staining is used for sub-typing of the tumor, predicts the prognosis of the tumor and also the response to the specific type of therapy.

Keywords: clear cell sarcoma, immunohistochemistry, sarcoma, diagnosis, soft tissue neoplasm, radiotherapy, chemotherapy, malignant melanoma

\section{Introduction}

Clear cell sarcoma is a translocation-associated sarcoma and a genetic mutation defines the disease. In chromosomal translocations, the pieces of two chromosomes are swapped, resulting in an abnormal fusion of genes. Clear cell sarcoma of the soft tissues in adults is not related to the clear cell sarcoma of the kidney, a pediatric tumor. Clear cell sarcoma has morphological similarity to malignant melanoma and is thought to derive from the migrated neural crest cells [1,2]. Clear cell sarcoma has main characteristic immunohistochemical, morphological, and utrastructural similarity to malignant melanoma [3]. Because of these melanocytic features, its distinction from malignant melanoma may be difficult $[4,5]$. Clear cell sarcoma of soft tissue arising from the hand and fingers is a rare presentation.

\section{1:1. Classification of clear cell sarcomas:}

Clear cell sarcoma is classified either by the site of origin or by translocation type. The classification is important for identifying the type of tumor and also helps in planning the therapeutic strategies.

\section{1:1:1. Types of clear cell sarcoma}

Based on their site of origin clear cell sarcoma are classified as (A) typical clear cell sarcoma of tendons and aponeuroses (B)gastrointestinal clear cell sarcoma and (C) Cutaneous clear cell sarcoma.

\section{1:1:2. Genetic classification}

- The most common types of clear cell sarcoma are associated with EWSR1/ATF1 or a EWSR1/CREB1 translocation.

- Sometimes these tumors present without EWSR1 translocation.

Clear-cell sarcoma is also known as malignant melanoma of the soft parts(MMSP) because of its melanotic and histologic similarities with conventional melanoma [6].Ipach et al. in 2012 identified these tumors as a rare form of sarcoma, that account for less than $1 \%$ of all malignant tumors in adult[7,8]. Primary Clear cell sarcoma usually occurs in deeper soft tissues, in association with fascia, tendons, or aponeuroses. It typically involves the extremities, especially tendons and aponeuroses of the foot and ankle. About $40 \%$ of cases are deep-seated in 
the foot and ankle, without involvement of the skin. [9]. These tumors are located in the deep soft tissues of the extremities, in the trunk or in limb girdles. The median tumor size is $4 \mathrm{~cm}$ (range: $1 \mathrm{~cm}$ to $15 \mathrm{~cm}$ ). They are aggressive tumors with high incidence rates of recurrence and metastasis. Clear cell sarcoma is a tumor of unknown etiology. This tumor affects all age groups but is more common in young adults, with a slight female predominance with peak incidence between ages of 20 and 40 years. Clinically, Clear cell sarcoma presents as a slow-growing but often painful nodule on the extremities $[10,11]$. Most cases occur in the lower extremities with approximately $40 \%$ of tumors in the foot and ankle, followed by the knee, thigh, forearm, elbow and shoulder. It is less common in the trunk, head and neck regions. Upper limb is affected in about $25 \%$ of cases but involvement of the hand and fingers is rare [12,13]. Incomplete excision of the tumor results in local recurrence and metastasis to lymph nodes, lungs or bones [14]. These tumors have high rate of local and regional recurrences in spite of radical ablative surgery and adjuvant therapy and tend to have poor prognosis. Diagnosis of clear cell sarcoma is difficult because of its slow growing nature, benign clinical appearance, lack of pigmentation in most cases and relatively young age presentation in patients [15].The differential diagnosis includes other soft tissue sarcomas like malignant fibrous histiocytoma, rhabdomyosarcoma, fibrosarcoma, liposarcoma, epithelioid sarcoma, and malignant schwannoma [16]. The differential diagnosis includes numerous benign conditions such as interdigital neuromas, nodular fasciitis, benign adnexal tumors and lipoma.

\section{Clinical case presentation}

A 21-year-old female presented with a painful recurrent lesion on the left middle finger of six years duration. There was a fusiform swelling measuring $4 \mathrm{~cm} \times 3 \mathrm{~cm}$ size involving the proximal and middle phalanx of the left mid finger(Figure:1).Patient gives history of previous surgical procedure four years back. The details of the surgery and histopathological reports are not available with the patient.
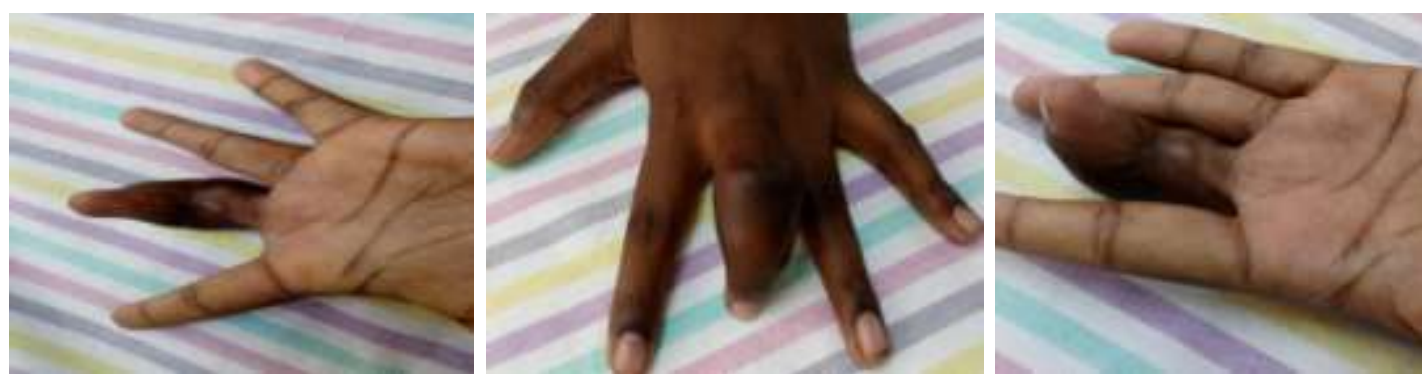

Fig: 1.Swelling of the left middle finger with involvement of proximal and middle phalanx.

There was no personal or family history of cutaneous malignancy in her family. Her vital signs were stable and the systemic examination was normal. There was no regional or distant lymphadenopathy. Investigations: Complete blood count, blood biochemistry, ultrasonography of abdomen and pelvis were normal.
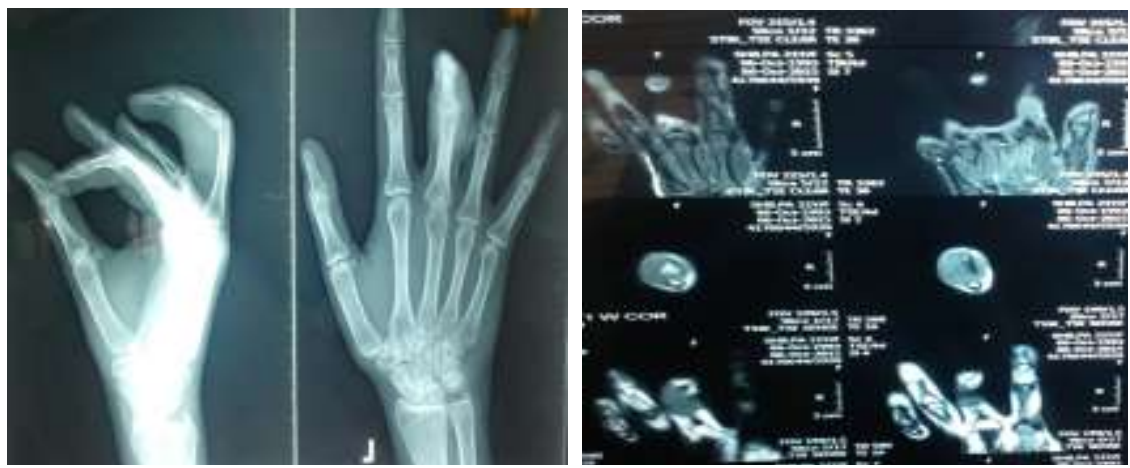

Fig: 2.Plain X-ray and MRI show the soft tissue swelling with normal architecture of the bones.

Plain X-ray of the left hand revealed normal bone structures. MRI of left hand showed soft tissue mass encasing the bone, suggestive of a soft tissue sarcoma from the deeper soft tissue layers of the finger (Figure:2).With a provisional diagnosis including fibrosarcoma, malignant edema, Clear cell sarcoma, tenosynovial sarcoma, and angiosarcoma the patient was planned for surgery. Ray amputation of the left mid finger was done and the excised specimen was sent for histopathological examination.

2:1. Histopathological examination of the excised specimen showed the tumor cells arranged in solid nests, infiltrating cords and in single.(Fig.3). These cells have moderate amount of eosinophilic cytoplasm, 
pleomorphic vesicular nuclei with prominent macro nucleoli (Fig.4).Few mitotic figures were noted. The stroma shows desmoplastic reaction with sparse mononuclear cell infiltration. No evidence of necrosis. The diagnostic options considered were soft tissue sarcoma possibly epithelioid tumor or metastatic deposits from a primary tumor.

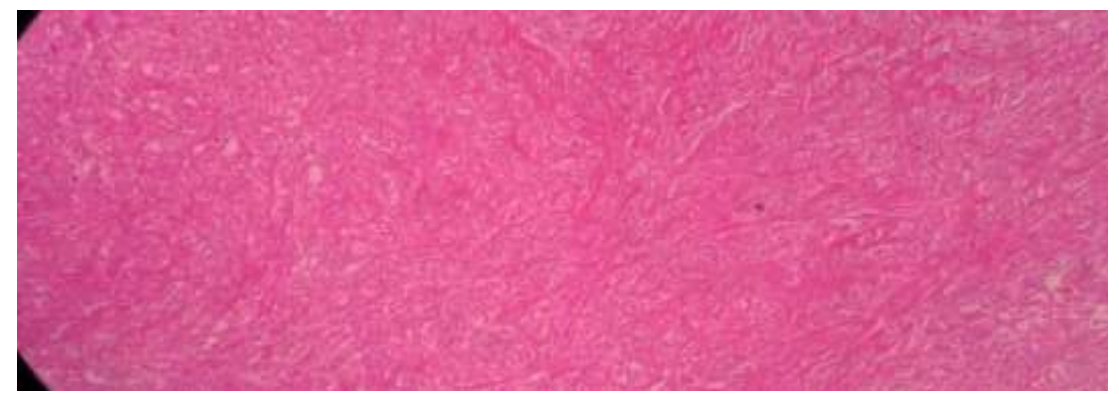

Fig: 3. Nests of tumor cells delineated by fibrous septa. (H\&E 10X).

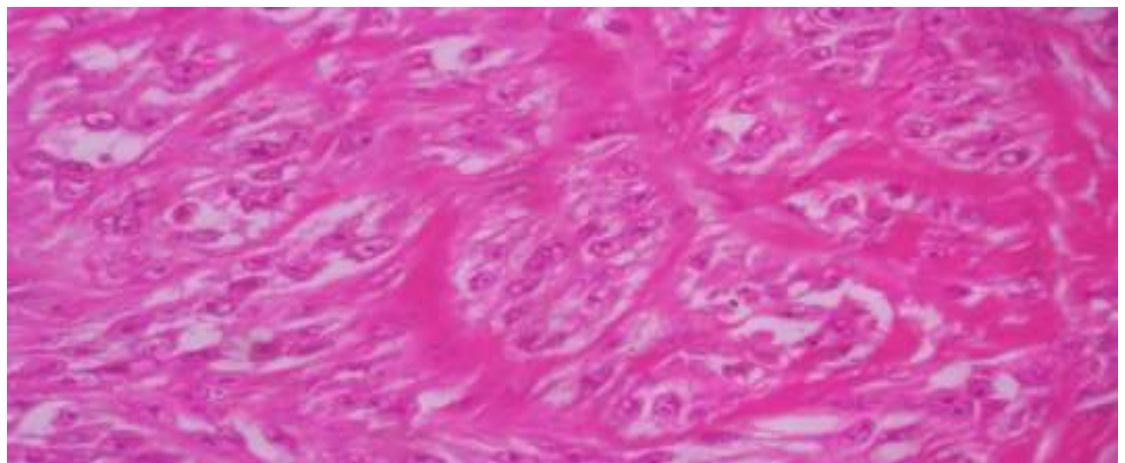

Fig: 4. Tumor cells with clear to eosinophilic cytoplasm, pleomorphic vesicular nuclei with prominent single nucleoli. (H\&E 40x).

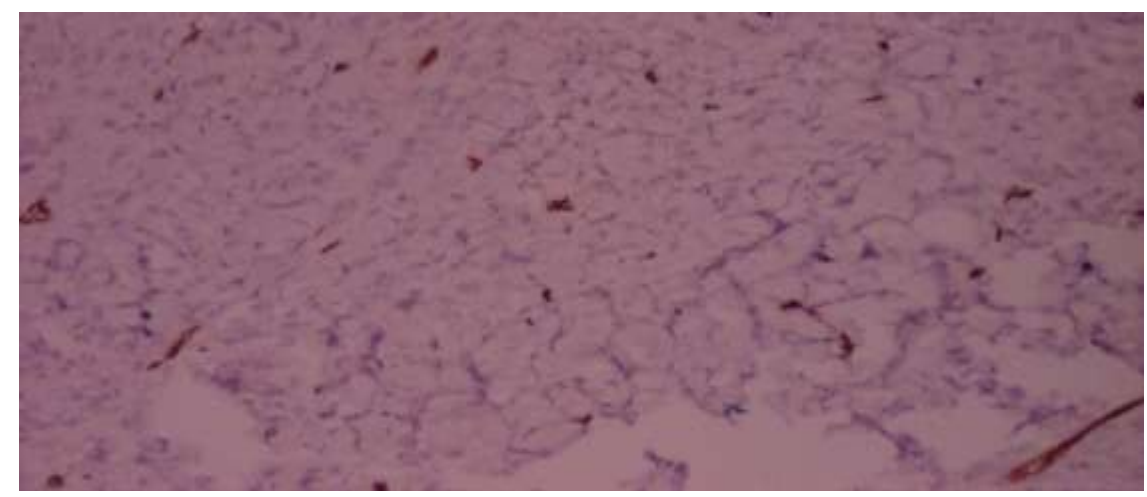

Fig: 5. IHC CD 31 - Non immuno-reactive in neoplastic cells.

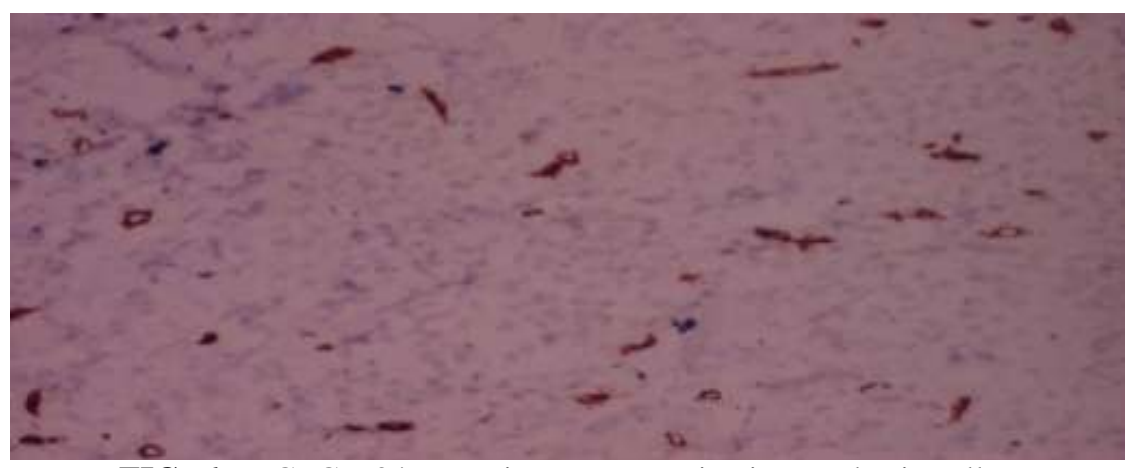

FIG: 6. IHC- CD 34 : Non immuno-reactive in neoplastic cells. 


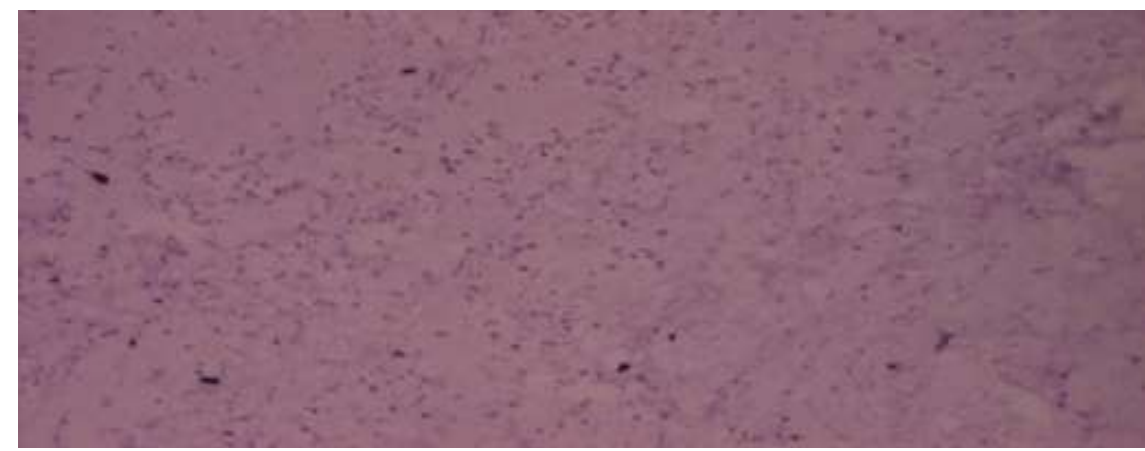

FIG:7. IHC- DESMIN : Non immuno-reactive in neoplastic cells.

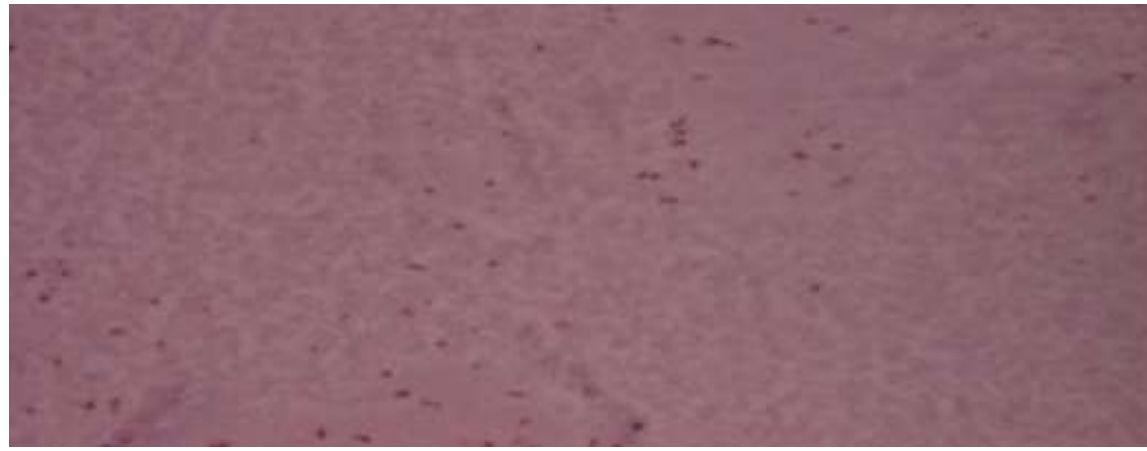

FIG: 8. IHC- SMA: Non immuno-reactive in neoplastic cells.

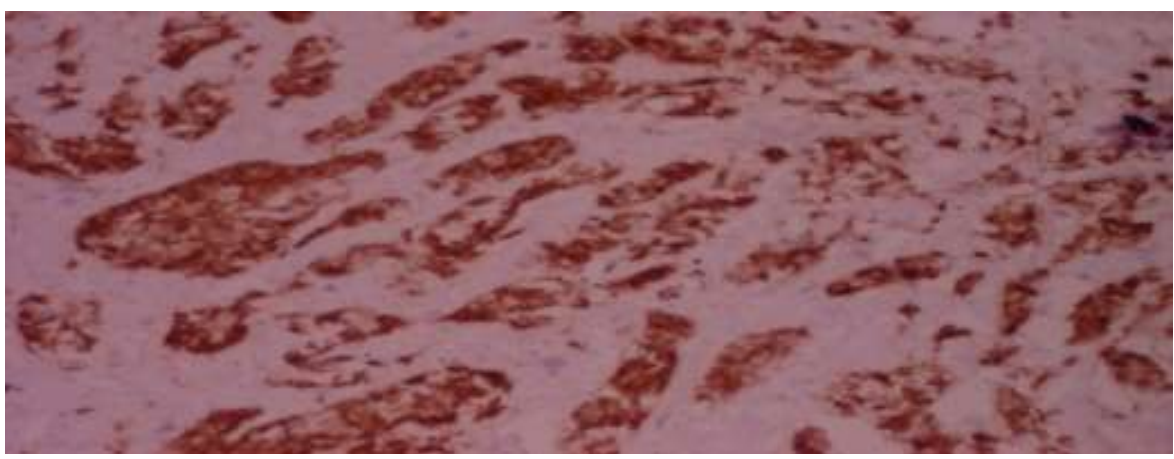

FIG: 9. IHC- HMB 45: Immuno-reactive in neoplastic cells, Score 3+.

Immunohistochemistry was done for sub-typing of the tumor with basic panel of tumor markers. Immunohistochemistry for HMB 45 identified $3+$ immuno-reactive in $51-75 \%$ of the neoplastic cells, morphologic and Immunohistochemistry features consistent with clear cell sarcoma of the soft tissues.(Fig. 9).The patient was referred to the oncology department for evaluation and follow-up chemo and radiotherapy.

\section{Discussion}

The differential diagnosis of a tumor located in close proximity to tendons and aponeuroses in an extremity includes

* paraganglioma-like dermal melanocytic tumor,

* clear cell myomelanocytic tumor,

* malignant peripheral nerve sheath tumor,

* monophasic synovial sarcoma,

* deep-seated epithelioid sarcoma,

* adult fibrosarcoma,

* psammomatous melanotic schwannoma, and

* Metastatic malignant melanoma.

\section{3:1. Diagnostic criteria of clear cell sarcoma}

It has been suggested that clear cell sarcoma may be diagnosed by

- cytology, 
- immunohistochemistry (HMB- 45+ and S-100+ stains),

- cytogenetic analysis will demonstrate the specific translocation and

- Electron microscopy will confirm the utrastructural evidence for the presence of melanosomes $[17,18,19]$.

\section{3:1:1.Histopathological features}

Sarcomas are very uniform in their appearances; clear cell sarcoma is identified by its histological patterns. According to Hersekli et al. (2005) "the gross appearance of clear cell sarcoma is usually of a lobular and well-bordered or encapsulated lesion. The tumor cells are polygonal or spindle-shaped and have eosinophilic or clear cytoplasm. The nuclei have one or two large nucleoli. Some tumor cells may contain melanin pigment". The tumor cells are either spindle or epithelioid in nature and they are arranged predominantly in a short fascicular or in a solid sheet like growth pattern. Minor histologic cell type variations seen are

$\checkmark$ rhabdoid cells

$\checkmark$ bizarre pleomorphic cells

$\checkmark$ alveolar structures due to loss of cellular cohesion and

$\checkmark$ A seminoma-like pattern.

Tumor necrosis was evident and the mitotic activity ranged from 0 to 43 mitotic figures (MF)/10 high-power fields (HPF).

\section{3:1:2. Immunohistochemistry of clear cell sarcoma}

- In tumor marker assessment of Clear cell sarcoma, Vimentin, HMB45 and S-100 are positive

- Negative for epithelial markers to rule out synovial sarcoma and

- Negative for FMA to rule out muscular tumors.

Immunohistochemically, the tumors were consistently positive for S-100 protein, variably or focally positive for HMB45 and alpha-Smooth muscle actin, desmin, and cytokeratin (CAM5.2) were negative. They may be also variably positive for the following markers: microphthalmia transcription factor, Melan A, CD57, bcl-2, synaptophysin, CD56, epithelial membrane antigen, cytokeratin (AE1/AE3), CD34, c-erbB-2, c-kit, and c-met.

Clear cell sarcoma shares a similar immunohistochemical profile with malignant melanoma with two exceptions:

I. CD68 is more specific for malignant melanoma and has not been reported positive in Clear cell sarcoma, and

II. Clear cell sarcoma displays occasional positivity for chromogranin while malignant melanoma does not. [20].

3:1:3. Distinction between clear cell sarcoma and malignant melanoma must be made because of their close similarities in histopathological appearances. (Table: 2).

\begin{tabular}{|l|l|l|l|}
\hline S.No & Features & Malignant Melanoma & Clear cell sarcoma \\
\hline 1 & Histopathological feature & Intraepidermal involvement(+) & $\begin{array}{l}\text { Fascia and aponeuroses involvement: } \\
\text { Deep seated: No direct connection to } \\
\text { epidermis }\end{array}$ \\
\hline 2 & Histopathologic criteria & $\begin{array}{l}\text { Melanocytic proliferation in the basal } \\
\text { cell layer }\end{array}$ & $\begin{array}{l}\text { Presence of spindle and clear cells, } \\
\text { absence of nuclear atypia and small and } \\
\text { inconspicuous nucleoli }\end{array}$ \\
\hline 3 & Cytogenetic features & BRAF or NRAS mutation +/- & $\begin{array}{l}\text { Characteristic translocation } \\
\text { t(12;22)(q13;q12)EWSR1/ATF1 gene } \\
\text { rearrangement }\end{array}$ \\
\hline 4 & IHC findings & CD68 is more specific for MM & $\begin{array}{l}\text { Immunopositive for S-100,HMB- } \\
\text { 45,Malan-A,Micropthalmia transcription } \\
\text { factor,bcl-2 and vimentin: viable positive } \\
\text { for synaptophysin,CD56 and EMA: } \\
\text { Rarely positive for AE1/AE3: And } \\
\text { immunonegetive for SMA,Desmin and } \\
\text { CAM5.2 }\end{array}$ \\
\hline 5 & Electron microscopy & $\begin{array}{l}\text { Melanosomes are present in great } \\
\text { numbers in the large pagetoid tumor } \\
\text { cell }\end{array}$ & $\begin{array}{l}\text { Supply utrastructural evidence for the } \\
\text { presence of melanosomes }\end{array}$ \\
\hline
\end{tabular}

Table: 1. Distinction between clear cell sarcoma and malignant melanoma.

BRAF: V-raf murine sarcoma viral oncogene homolog B, NRAS: Neuroblastoma RAS viral ( v-ras) oncogene homolog, EMA: Epithelial membrane antigen, SMA: Smooth muscle actin, HMB:A relatively specific melanoma marker,EWSR1/ATF1: EWS RNA-binding protein 1/ activating transcription factor 1. 
3:1:3:1. Histopathological criteria that support the classification of clear cell sarcoma as a separate entity include the

$\checkmark$ presence of spindle and clear cells,

$\checkmark$ absence of nuclear atypia, and

$\checkmark$ Small inconspicuous nucleoli.

\section{3:1:3:2. Malignant melanoma is characterized by an}

$\checkmark$ Intraepidermal component.

$\checkmark$ Although it is not necessary, lack of pigmentation is expected in malignant melanoma.

$\checkmark$ Junctional activity can be observed in the tumor, with nests of proliferating melanocytic cells showing cytologic atypia in the basal layer [21].

\section{3:1:3:3. Immunohistochemical study plays an important role in the differentiation.}

$\checkmark$ Clear cell sarcoma of soft tissue is usually immuno-positive for S-100, HMB-45, melan-A, microphthalmia transcription factor, bcl-2, and vimentin;

$\checkmark$ viable positive for synaptophysin, CD56, and epithelial membrane antigen (EMA);

$\checkmark$ Rarely positive for AE1/AE3; and immuno-negative for smooth muscle actin (SMA), desmin, and CAM5.

Morphologically, the uniform nature of the tumor cells, lack of pagetoid spread, and presence of scattered wreath-like multinucleated cells are features which should prompt consideration of a diagnosis of clear cell sarcoma over a melanoma.

\section{3:2. Diagnostic tests for clear cell sarcoma}

- Plain X-rays

- Computed tomography scans

- Magnetic resonance imaging scans

- Ultrasound

- Positron emission tomography scan

- Biopsy

Biopsy samples are analyzed for the Grading of the sarcoma. Immunohistochemistry, cytogenetic, Fluorescent in situ hybridization (FISH) and reverse transcription polymerase chain reaction (RT-PCR) methods are used for analyzes. Fluorescence in situ hybridization Test: Translocation $\mathrm{t}(12 ; 22)(\mathrm{q} 13 ; \mathrm{q} 12)$ can be detected by cytogenetic analysis performed using a single-stranded probe- the LSI CHOP (12q13) Dual Color, Break Apart Rearrangement Probe.

\section{3:3. Prognostic factors}

Prognosis of clear cell sarcoma depends on the size of the tumor mass and presence of metastasis. Metastatic tumor is very aggressive. Poor prognosis is associated with

$\checkmark$ tumor size larger than $5 \mathrm{~cm}$

$\checkmark$ presence of necrosis,

$\checkmark$ metastasis, and

$\checkmark$ Local recurrence.

3:4. Survival rate for Clear cell sarcoma of soft tissue tumor at 5, 10, and 20 years was reported as 67,33 , and $10 \%$ respectively.

\section{Treatment of clear cell sarcoma of soft tissue}

The phase of clear cell sarcoma is determined by a combination of location of the tumor, size of the tumor, presence or absence of metastasis, aggressive appearance of the tumor, histology of the tissue and immunohistochemistry.

\section{4:1. Chemotherapy:}

All positive factors are put together to form a treatment plan by the oncologist. The most effective treatment of a clear cell sarcoma is the complete surgical resection of the tumor as soon as the diagnosis is made. Poor prognosis is associated with tumor size larger than $5 \mathrm{~cm}$ and presence of necrosis, metastasis, and local recurrence [22]. Like melanoma, the clear cell sarcoma is believed to originate from migrated neural crest cells, and it has been thought that these tumors might respond better to biochemotherapy regimens used typically for malignant melanoma, rather than Adriamycin and ifosfamide based regimens used more commonly in the treatment of soft tissue sarcomas. Limb-sparing surgery combined with radiotherapy provides excellent local control outcomes with preservation of limb function, for sarcomas arising in the hands or feet. For patients 
with local recurrence, salvage without amputation is possible. Patients in advanced stages of tumor were treated with amputation/disarticulation. Remissions in metastatic clear cell sarcomas after the use of interferon-alpha $2 \mathrm{~b}$ with chemotherapy have been reported [23, 24]. Hence, interferon was included in the metastatic melanoma regimen [25].

\section{4:1:1. chemotherapeutic regimen}

Various chemotherapeutic regimens used for musculoskeletal sarcoma are employed in the treatment of clear cell sarcoma also. Chemotherapeutic agents used for treatment of malignant melanoma are combinations of dacarbazine, nimustine, vincristine and interferon-alpha

- Doxorubicin as a single agent $-60-90 \mathrm{mg} / \mathrm{m}^{2}$

- Doxorubicin $60 \mathrm{mg} / \mathrm{m}^{2}+$ ifosfamide $5-9 \mathrm{~g} / \mathrm{m}^{2}$

- Doxorubicin $60 \mathrm{mg} / \mathrm{m}^{2}+$ cisplatin $120 \mathrm{mg} / \mathrm{m}^{2}$

\section{4:1:2. Caffeine-assisted chemotherapy}

- $\quad 3-5$ courses of cisplatin $120 \mathrm{mg} / \mathrm{m}^{2}+$ doxorubicin $30 \mathrm{mg} / \mathrm{m}^{2}$ for 2 days + caffeine $1.5 \mathrm{~g} / \mathrm{m}^{2}$ for 3 days

4:2. Radiotherapy (external-beam irradiation with mega-voltage beams) was used. The median radiotherapy dose was 45 grays (Gy) (33 Gy for preoperative irradiation, 60 Gy for postoperative irradiation).

\section{Future perspectives}

There are over 100 different subtypes of bone and soft tissue sarcomas. Soft tissue sarcomas as a class of tumors have a low response rate to chemotherapies and each subtype responds differently to chemotherapy. The tumor biology of each sarcoma subtype is different making the development of histologically driven or pathway-specific targeted therapies key to the future of soft tissue sarcoma treatment. Identification of molecular targets for specific subtypes of sarcomas could prove to be useful in treatment of sarcoma in future (Table: 2).

\begin{tabular}{|l|l|l|}
\hline S.No & Sarcoma subtype & Molecular target \\
\hline 1 & De-differentiated Liposarcoma & $\begin{array}{l}\text { Murine double minute gene (MDM2) and cyclin- } \\
\text { dependent kinase 4 (CDK4) amplification }\end{array}$ \\
\hline 2 & Myxoid Liposarcoma & FUS-CHOP gene fusion oncoprotein \\
\hline 3 & Solitary fibrous tumors & NAB2-STAT6 gene fusion oncoprotein \\
\hline 4 & Synovial sarcoma & SYT-SSX gene fusion oncoprotein \\
\hline 5 & Alveolar rhabdomyosarcoma & PAX3-FOXO1 (P3F) gene fusion oncoprotein \\
\hline 6 & Angiosarcoma & Angiopoeitin-TIE2 pathway \\
\hline 7 & Malignant peripheral sheath tumors & mTOR pathway \\
\hline
\end{tabular}

Table: 2. Novel pathways and molecular targets for the treatment of sarcoma (Adopted from Hendifar et al. Annals of cancer research 2015 2: 5)

\section{Conclusion}

Clear cell sarcoma of soft tissue is a rare, highly malignant soft tissue tumor that occurs most commonly in the extremities; the majority of patients are young women. When a fast-growing (i.e., a few months) and rapidly ulcerating, large nodular lesion is detected in a tendon or aponeuroses of a young- to middle-aged patient, it should always raise suspicion of Clear cell sarcoma of soft tissue. Clear cell sarcoma is an aggressive soft tissue tumor with a melanocytic phenotype with wider morphologic variations. Clear cell sarcoma is a recently described variant of sarcoma characterized by prominent clear cell features similar to clear cell melanoma [26]. Clear cell sarcoma tumor can lay in-situ for many years without any complication or change in size and then starts to grow rapidly. A history of trauma is not uncommon in clear cell sarcoma and is known to appear mostly in lower extremities. It can also rarely occur in the hand, wrist and fingers [27]. In cases with unusual histologic findings, molecular detection of the EWSR1-ATF1/CREB1 fusion genes provides critical information regarding the diagnosis of the tumor.

\section{References}

[1]. Enzinger FM. Clear-cell sarcoma of tendons and aponeuroses. An analysis of 21 cases. Cancer.1965;18:1163-74. [PubMed]

[2]. Lasithiotakis K, Protonotarios A, Lazarou V, Tzardi M, Chalkiadakis G. Clear cell sarcoma of the jejunum: A case report. World J Surg Oncol. 2013;11:7. [PMC free article] [PubMed]

[3]. Hantschke M, Mentzel T, Rutten A, Palmedo G, Calonje E, Lazar AJ, et al. Cutaneous clear cell sarcoma: A clinicopathologic, immunohistochemical, and molecular analysis of 12 cases emphasizing its distinction form dermal melanoma. Am J Surg Pathol. 2010;34:216-22. [PubMed]

[4]. Crowson A, Magro C, Mihm MC., Jr Unusual histologic and clinical variants of melanoma: Implications for therapy. Curr Oncol Rep. 2007;9:403-10. [PubMed] 
[5]. Panagopoulos I, Mertens F, Isaksson M, Mandahl N. Absence of mutations of the BRAF gene in malignant melanoma of soft parts (clear cell sarcoma of tendons and aponeuroses) Cancer Genet Cytogenet.2005;156:74-6. [PubMed]

[6]. Hermann G, Klein MJ, Springfield DS, AbdelwahabIF. Clear cell sarcoma (malignant melanoma of soft parts): case report and review of the literature. Can Assoc Radiol J. 2002 Oct;53(4):237-240.

[7]. Enzinger FM. Clear cell sarcoma of tendons and aponeuroses: an analysis of 21 cases. Cancer. 1965; 18:1163-74.

[8]. Chung EB, Enzinger FM. Malignant Malignant melanoma of soft parts. A reassessment of clear cell sarcoma. Am J Surg Pathol. 1983;7(5):405-13.

[9]. Hisaoka M, Ishida T, Kuo TT, Matsuyama A, Imamura T, Nishida K, et al. Clear cell sarcoma of soft tissue: A clinicopathologic, immunohistochemical, and molecular analysis of 33 cases. Am J Surg Pathol.2008;32:452-60. [PubMed]

[10]. Enzinger FM. Clear cell sarcoma of tendons and aponeuroses: An analysis of 21 cases. Cancer. 1965;18:1163-76. [PubMed]

[11]. Hisaoka M, Ishida T, Kuo TT, Matsuyama A, Imamura T, Nishida K, et al. Clear cell sarcoma of soft tissue: A clinicopathologic, immunohistochemical, and molecular analysis of 33 cases. Am J Surg Pathol. 2008;5:27-35. [PubMed]

[12]. Tyler G, Wirman J, Neale HW. Melanin containing clear cell sarcoma in a fingertip. Case report and review of the literature. Hand. $1980 ; 12(3): 308-15$.

[13]. Kawai A, Hosono A, Nakayama R, Matsumine A, Matsumoto S, Ueda T, et al. Clear cell sarcoma of tendons and aponeuroses A study of patients. Cancer. 2007;109:109-16. [PubMed]

[14]. Lucas DR, Nascimento AG, Sim FH. Cell sarcoma of soft tissues: Mayo Clinic experience with 35 cases. Am J Surg Pathol. 1992;16:1197-204. [PubMed]

[15]. Mackey SL, Hebel J, Cobb MW. Melanoma of the soft parts (clear cell sarcoma) : a case report and review of literature. J Am Acad Dermatol 1998; 38:815-19.

[16]. Prieskorn DW, Irwin RB, Hankin R. Clear cell sarcoma presenting as an interdigital neuroma. Orthop

[17]. Review 1992;21(8):963-70.

[18]. Crowson A, Magro C, Mihm M. Unusual histologic and clinical variants of melanoma: Implications for therapy. Curr Oncol Rep. 2007;9:403-10. [PubMed]

[19]. Magro CM, Crowson AN, Mihm MC. Unusual variants of malignant melanoma. Mod Pathol. 2006;19:S41-70. [PubMed]

[20]. Furuya M, Shimizu M, Nishihara H, Ito T, Sakuragi N, Ishikura H, et al. Clear cell variant of malignant melanoma of the uterine cervix: A case report and review of the literature. Gynecol Oncol. 2001;80:409-12. [PubMed.

[21]. Eckardt JJ, Pritchard DJ, Soule EH. Clear cell sarcoma: A clinicopathologic study of 27 cases. Cancer. 1983;52:1482-8. [PubMed]

[22]. Dim DC, Cooley LD, Miranda RN. Clear cell sarcoma of tendons and aponeuroses: A review. Arch Pathol Lab Med. 2007;131:152-6. [PubMed].

[23]. Jones RL, Constantinidou A, Thway K, Ashley S, Scurr M, Al-Muderis O, et al. Chemotherapy in clear cell sarcoma. Med Oncol. 2011;28:859-63. [PubMed]

[24]. Lauro S, Bordin F, Trasatti, Lanzetta G, Della Rocca C, Frati L. Concurrent chemoimmunotherapy in metastatic clear cell sarcoma: A case report. Tumori 1999;85:5124.

[25]. Steger GG, Wrba F, Mader R, Schlappack O, Dittrich C, Rainer H. Complete remission of metastasised clear cell sarcoma of tendons and aponeuroses. Eur J Cancer 1991;27: 2546.

[26]. Anderson C, Buzaid A, Legha S. Systemic treatments for advanced cutaneous melanoma. Oncology 1995;9:114958.

[27]. Menzel T. Uncommon variants of malignant melanocytic neoplasms. Pathologe. 2007;12 [PubMed] 